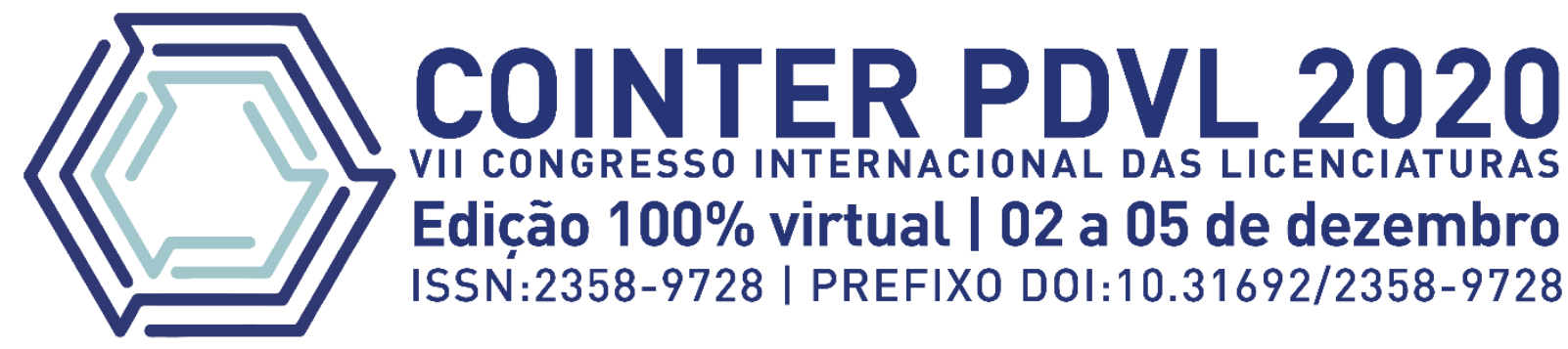

\title{
DIREITOS HUMANOS NO CURSO DE LICENCIATURA EM QUÍMICA DO IFPI CAMPUS TERESINA CENTRAL
}

\section{DERECHOS HUMANOS EN EL CURSO DE LICENCIA DE QUÍMICA CENTRAL DE IFPI CAMPUS TERESINA}

\section{HUMAN RIGHTS IN THE IFPI CAMPUS TERESINA CENTRAL CHEMISTRY LICENSING COURSE}

\author{
Apresentação: Comunicação Oral \\ Raiane de Oliveira Araujoㅜ; Vanessa Nunes dos Santos ${ }^{2}$
}

DOI: https://doi.org/10.31692/2358-9728.VIICOINTERPDVL.0255

\section{RESUMO}

A formação de educadores em direitos humanos pode orientá-los a ideia de transversalidade e interdisciplinaridade. Essas dimensões pedagógicas possibilitam, orientar os currículos escolares a fomentar uma cultura de direitos, uma vez que permitem a implantação dos conceitos dos direitos humanos em todas as disciplinas dos cursos de graduação e em toda a forma organizacional dos programas de formação continuada. A educação em direitos humanos emergiu como um potencial significativo no contexto de busca por um novo estado de direito, e tem ganhado maior visibilidade e importância na perspectiva de formação docente dentro das academias. As instituições de ensino possuem uma grande responsabilidade na criação de espaços para a cultura de Direito Humanos, estes devem estar nos currículos, nas avaliações, na capacitação de professores e outros. Deste modo, foi desenvolvida esta pesquisa com o objetivo de compreender a proposta de formação docente para atuação na perspectiva da educação para a diversidade e inclusão do curso de licenciatura em química ofertada pelo Instituto. Em função da natureza do objeto de estudo, foi abordada a questão dos direitos humanos, trazendo uma análise do currículo do curso de licenciatura em química do IFPI Campus Teresina Central, refletindo como ele prepara (ou deveria preparar) um professor com formação humanista. A questão norteadora da pesquisa é: qual a fundamentação que um licenciando recebe para lidar com questões como direitos humanos, políticas de inclusão, sociedade e meio ambiente? Conclui-se desse modo, que o currículo é uma construção permanente o Projeto político pedagógico do Curso de Licenciatura em química desde sua implantação vem sendo adequado conforme as políticas e demandas na formação de professores. Portanto, conclui-se que tal processo formativo a qual está centrado a questão dos direitos humanos na formação docente é uma das etapas fundamentais para que o professor, no futuro, se veja como um profissional atuante como Agente Sociocultural e Político, vindo a dar voz aos diversos grupos sociais e questionando as desigualdades sociais existentes, lutando pelo

\footnotetext{
${ }^{1}$ Licenciatura em química, Instituto Federal do Piauí - Teresina Central, raiane1935@gmail.com.

${ }^{2}$ Doutoranda, Universidade Federal do Piauí, vanessanunes@ifpi.edu.com.br
} 


\section{DIREITOS HUMANOS NA FORMAC̨ÃO DOS ALUNOS DO IFPI}

enfrentamento da equidade desses grupos na sociedade, buscando por uma sala de aula pautada no diálogo entre os diversos saberes e vivências que traga o estudante como sujeito ativo de uma reivindicação necessária e de uma mudança possível.

Palavras-Chave: Direitos humanos, formação docente, currículo, projeto pedagógico.

\section{RESUMEN}

La formación de educadores en derechos humanos puede orientarlos hacia la idea de transversalidad e interdisciplinariedad. Estas dimensiones pedagógicas permiten orientar los currículos escolares para fomentar una cultura de derechos, ya que permiten la implementación de conceptos de derechos humanos en todas las disciplinas de los cursos de pregrado y en toda la forma organizativa de los programas de educación continua. La educación en derechos humanos ha surgido como un potencial significativo en el contexto de la búsqueda de un nuevo estado de derecho, y ha ganado mayor visibilidad e importancia en la perspectiva de la formación docente dentro de las academias. Las instituciones educativas tienen una gran responsabilidad en la creación de espacios para la cultura del Derecho Humano, estos deben estar en los planes de estudio, en las evaluaciones, en la formación de docentes y otros. De esta manera, esta investigación se desarrolló con el objetivo de comprender la propuesta de formación docente para actuar en la perspectiva de la educación para la diversidad y la inclusión de la carrera de Química que ofrece el Instituto. Por la naturaleza del objeto de estudio, se abordó el tema de los derechos humanos, trayendo un análisis del plan de estudios del curso de química en la IFPI Campus Teresina Central, reflejando cómo se prepara (o debe preparar) un docente con formación humanística. La pregunta orientadora de la investigación es: ¿cuál es la base que recibe un licenciatario para abordar temas como los derechos humanos, las políticas de inclusión, la sociedad y el medio ambiente? Se puede concluir, por tanto, que el currículo es una construcción permanente. Por tanto, se concluye que dicho proceso formativo, centrado en la temática de los derechos humanos en la formación docente, es uno de los pasos fundamentales para que el docente, en el futuro, se vea como un profesional activo como Agente Sociocultural y Político, llegando a dar voz. a los diferentes grupos sociales y cuestionando las desigualdades sociales existentes, luchando por afrontar la equidad de estos grupos en la sociedad, buscando un aula basada en el diálogo entre los diversos saberes y experiencias que trae al alumno como sujeto activo de una reivindicación necesaria y un posible cambio.

Palabras clave: derechos humanos, formación docente, currículo, proyecto pedagógico.

\section{ABSTRACT}

The training of human rights educators can guide them to the idea of transversality and interdisciplinarity. These pedagogical dimensions make it possible to guide school curricula to foster a culture of rights, since they allow the implementation of human rights concepts in all disciplines of undergraduate courses and in the entire organizational form of continuing education programs. Human rights education has emerged as a significant potential in the context of the search for a new rule of law, and has gained greater visibility and importance in the perspective of teacher training within the academies. Educational institutions have a great responsibility in creating spaces for the culture of Human Law, these must be in the curricula, in the evaluations, in the training of teachers and others. In this way, this research was developed with the objective of understanding the proposal of teacher training to act in the perspective of education for diversity and inclusion of the degree course in Chemistry offered by the Institute. Due to the nature of the object of study, the issue of human rights was addressed, bringing an analysis of the curriculum of the degree course in chemistry at the IFPI Campus Teresina Central, reflecting how it prepares (or should prepare) a teacher with humanistic training. The guiding question of the research is: what is the foundation that a licensee receives to deal with issues such as human rights, inclusion policies, society and the environment? It is concluded, therefore, that the curriculum is a permanent construction. The Political Pedagogical Project of the Degree Course in Chemistry since its implementation has been adequate according to the policies and demands in the training of teachers. Therefore, it is concluded that such a formative process which is 
centered on the issue of human rights in teacher education is one of the fundamental steps for the teacher, in the future, to see himself as an active professional as a Sociocultural and Political Agent, coming to give a voice to the different social groups and questioning the existing social inequalities, fighting to face the equity of these groups in society, searching for a classroom based on the dialogue between the diverse knowledge and experiences that brings the student as an active subject of a necessary claim and a possible change.

Keywords: Human rights, teacher training, curriculum, pedagogical project. 


\section{DIREITOS HUMANOS NA FORMAC̨ÃO DOS ALUNOS DO IFPI}

\section{INTRODUÇÃO}

As experiências pioneiras de educação em direitos humanos ocorreram no Brasil, bem como em quase toda a América Latina, após a década de 1980, momento marcado pela luta para a redemocratização após períodos de ditaduras militares (SACAVINO, 2016). De acordo com Candau e Sacavino (2000), a educação em direitos humanos emergiu como um potencial significativo no contexto de busca por um novo estado de direito, num momento em que emergiu com vigor a esperança da idealização de uma nova cultura política.

Norberto Bobbio (1992) corrobora com afirmativa de que os direitos humanos não nascem todos de uma vez e nem de uma vez por todas, partindo do princípio de que os direitos humanos não estão prontos, mas são reconstruídos conforme os acontecimentos históricos, tal qual a necessidade da humanidade e segundo as lutas libertárias e emancipatórias pela sua radicação, lutar por direitos humanos é lutar por reconhecimento. É, simultaneamente, defrontar todo e qualquer tipo de violação dos direitos já alcançados e lutar para instituir novas prerrogativas.

Dois eventos internacionais tiveram bastante relevância e podem ser considerados marcos dessas discussões no Brasil: a Conferência Mundial sobre Educação para Todos (UNESCO, 1990) e a Conferência Mundial sobre Necessidades Educacionais Especiais: Acesso e Qualidade, na qual foram aprovados a Declaração de Salamanca e o Marco de Ação para as Necessidades Educacionais Especiais (UNESCO, 1994). O Brasil, ao tornar-se signatário das Declarações da Unesco (1990, 1994), consolidou, portanto, o compromisso internacional de ofertar a educação a todos os brasileiros a partir de escolas inclusivas.

A educação é uma ferramenta indispensável para que o indivíduo possa reconhecer a si próprio como agente ativo na modificação da mentalidade do grupo no qual está inserido e ser promotor dos ideais humanos, a incorporação das Diretrizes Nacionais para a educação em direitos humanos nos projetos pedagógicos das instituições de ensino cumprem o papel de romper a rigidez da educação tradicional, considerando as experiências de vida desses sujeitos, fazem com que estes percebam os seus direitos (BRASIL, 2013).

A educação em direitos humanos (EDH) enquanto uma proposta de política pública foi fomentada no cenário nacional com a instituição do Comitê Nacional de Educação em Direitos humanos - CNEDH e posteriormente com a elaboração e publicação do Plano Nacional de 
Educação em direitos humanos, esse plano é um instrumento que orienta as ações educativas no âmbito de educação em direitos humanos com o propósito de nortear a formação de sujeitos de direitos, voltados para os reais compromissos sociais (BRASIL,2013).

A Constituição Federal de 1988 declara os direitos humanos, a democracia, a paz, e o desenvolvimento econômico como aspectos fundamentais com a finalidade de promover a garantia da dignidade da pessoa humana. Dentro dessa perspectiva, a educação se configura como uma ação essencial que permite o acesso efetivo a todos os direitos. As instituições de ensino, desde escolas básicas até as de ensino superior, devem direcionar seus projetos pedagógicos para os direitos humanos, preocupando-se não só com os conteúdos, mas também para a formação do caráter e da personalidade das pessoas (BRASIL, 2013).

A formação de educadores em direitos humanos pode orientá-los, segundo Dias e Porto (2010), a ideia de transversalidade e interdisciplinaridade. Essas dimensões pedagógicas podem, de acordo com as autoras, direcionar os currículos escolares com a finalidade de favorecer uma cultura de direitos, uma vez que possibilitam a implantação dos conceitos dos direitos humanos em todas as disciplinas dos cursos de graduação e em toda a forma organizacional dos programas de formação continuada, criando um vínculo entre as diversas discussões, para melhor compreensão do mundo atual.

As instituições de ensino apresentam imensa responsabilidade na implementação de espaços para a promoção da cultura de direitos humanos. Estes devem estar inseridos em projetos pedagógicos, nos currículos, nas avaliações, em produções de materiais pedagógicos e na capacitação e formação continuada dos professores. É oportuna a inclusão dessa temática para a sociedade civil através dos conselhos escolares (BRASIL, 2013).

A formação de professores(as) não deverá estar pautado em métodos padronizados, mas nas especificidades e singularidades do grupo que está recebendo a formação, de forma que cada membro do quadro docente venha a ser autor(a) do processo educacional emergente, isto é, do processo educacional que busca a efetivação de uma cultura de direitos humanos (MACIEL, 2016).

Nesse sentido, foi desenvolvida esta pesquisa com o objetivo de compreender a proposta de formação docente para atuação na perspectiva da educação para a diversidade do curso de licenciatura em química ofertada pelo Instituto Federal do Piauí-Campus Teresina Central por meio de análises referentes ao currículo do curso e do seu projeto pedagógico. 


\section{DIREITOS HUMANOS NA FORMAC̨ÃO DOS ALUNOS DO IFPI}

\section{FUNDAMENTAÇÃO TEÓRICA}

É indispensável pensar o docente como agente que cumpre o papel social de transformação, em articulação com seu tempo e contexto histórico o qual está inserido, situando-se como profissional que articula processos críticos de compreender a realidade e de tomar decisões acerca dos fatos, decisões estas pautadas na promoção de respeito mútuo no ambiente escolar, fatos estes que promovem o fortalecimento dos processos emancipatórios e de inclusão, de acordo com Fialho, Sousa e Lopes (2019) por meio da educação em direitos humanos, os sujeitos são estimulados a enxergar a si e ao próximo como cidadãos de direitos.

A questão do processo de formação de professores a partir da educação em direitos humanos é abordada por Candau et al. (2013) por meio de uma compreensão da realidade do contexto atual, este é marcado por intenso interesse e consciência sobre os direitos humanos e, ironicamente, por sucessivas violações dessas prerrogativas, influenciadas por uma dimensão cultural onde não é possível reduzir a totalidade das lutas sociais a aspectos econômicos.

Nesta perspectiva, de acordo com Dias e Porto (2010) a inserção da temática dos direitos humanos na formação de professores tem por finalidade superar a compreensão da formação de professores sobre educação em direitos humanos como apenas um direito formal, em que se reproduzem conhecimentos e técnicas incapazes de desconstruir pré-conceitos implícitos às práticas monoculturais e (neo)tecnicistas.

Considerando que a prática educativa emancipatória precisa ser identificada e vivenciada nos tempos e espaços de formação, percebe-se uma intenção evidente e necessária na qual a tranformação da mentalidade decorrente da construção de uma cultura de direitos, pautada por meio do paradigma dos direitos humanos e, por consequência, uma educação problematizadora, dialógica, humanizadora (DIAS; PORTO, 2010).

Viabilizar a implantação de uma educação/formação em direitos humanos, como um processo sistemático e multidimensional que orienta a formação do sujeito de direitos (PNEDH, 2007), pressupõe mudanças significativas tendo em vista a superação das marcas do processo colonialista: padronizador, sexista, homogeneizador e discriminador que limita compreensões de um contexto significativamente constituído pela diversidade cultural.

O processo de formação de professores para a questão de direitos humanos, inclusão e para o respeito à diversidade vinculadas ao ensino dos conteúdos curriculares é um dever 
intríseco da escola de acordo com Marques (2012) deve ser consolidado pela prática da Educação em direitos humanos. Na perspectiva de Magri (2012), a EDH tem por finalidade provocar nos sujeitos a percepção dos direitos de si e do próximo, resultando, dessa maneira, na formação cidadã. A formação acontece por meio da escolarização formal - aquela desenvolvida nos espaços institucionalizados - e também por meio da educação informal, que abarca toda a vivência social. Portanto, é necessário refletir o papel da formação docente para as questões de direitos humanos, inclusão e diversidade nessa missão.

Uma das ferramentas que permite a discussão dos direitos humanos é o Projeto político pedagógico (PPP) que é compreendido como um documento que, depois de construído, deverá nortear todas as ações da instituição. Gadotti (1994) afirma que sua elaboração dá-se na coletividade e está diretamente relacionada a uma ação de planejamento e, quando inserido na educação superior, possui o mesmo aspecto, obviamente, com sua especificidade, intitulado por Projeto pedagógico, Projeto Institucional, Projeto Educacional ou Projeto político pedagógico.

De acordo com Gadotti (1994) os projetos políticos pedagógicos prevê rupturas com o presente e promessas para o futuro. Projetar exprime tentar romper um estado confortável para arriscar-se, atravessar um período de instabilidade e analisar uma atual permanência em função da promessa de que cada projeto contém um estado melhor no presente. Um projeto educativo pode ser considerado como promessa para o futuro frente à algumas rupturas. As promessas tornam visíveis os campos de ação, comprometendo os sujeitos envolvidos.

O pensamento de Gadotti (1994) corrobora o de Veiga (2004) no sentido de que o projeto pedagógico é um processo de desenvolvimento institucional ou de curso em um determinado tempo e espaço. Esse processo é traduzido continuamente por meio de decisões a serem desenvolvidas de forma sistemática por coordenadores, professores, alunos e técnicos entre outros sujeitos envolvidos nesse processo, tendo como embasamento um dado contexto social. 


\section{DIREITOS HUMANOS NA FORMAC̨ÃO DOS ALUNOS DO IFPI}

\section{METODOLOGIA}

Em função da natureza do objeto de estudo que orienta esta pesquisa, foi abordada a questão dos direitos humanos, trazendo uma análise do currículo do curso de licenciatura em química. A questão norteadora da pesquisa é: qual a fundamentação que um licenciando recebe para lidar com questões como direitos humanos, políticas de inclusão e diversidade?

Desta forma, adotou-se uma metodologia com enfoque na pesquisa documental, que de acordo com Gil (2008) esse tipo de pesquisa está fundamentada na análise de documentos, a pesquisa documental vale-se de materiais que não receberam ainda um tratamento analítico, ou que ainda podem ser reelaborados de acordo com os objetivos da pesquisa.

Inicialmente, foi analisado o currículo do curso de Licenciatura em química. A observação da matriz curricular estava centrada na análise das disciplinas que fomentam o caráter da educação em direitos humanos e a educação na diversidade. Desta forma, após trazer uma crítica aos currículos de licenciatura em química.. A questão norteadora da pesquisa é: qual a fundamentação que um licenciando recebe para lidar com questões como direitos humanos, políticas de inclusão, sociedade e meio ambiente? Esta análise do projeto pedagógico e matriz curricular foi desenvolvida a partir das competências e habilidades propostas para o desenvolvimento dessas disciplinas no curso de Química.

Posteriormente, analisou-se o projeto pedagógico do curso de licenciatura em química, a análise documental foi pautada na observação das disciplinas que possibilitam a formação voltada para os direitos humanos. A análise do projeto pedagógico do curso(PPC) foi utilizada com a finalidade de analisar a aproximação entre teorias, documentos e práticas. Desta forma, buscou-se identificar os elementos presentes no PPC como também identificar quais os âmbitos norteadores estão mais próximos ou mais distantes de uma educação orientada por princípios da Educação em direitos humanos. 


\section{RESULTADOS E DISCUSSÃO}

Inicialmente, foi analisada a matriz curricular do curso de licenciatura em química do IFPI Campus Teresina Central, esta análise compreendeu a identificação das disciplinas dentro do currículo do curso que viabilizasse a discussão dos direitos humanos dentro do processo de formação docente do profissional de Química, posteriormente estas disciplinas foram localizadas no projeto pedagógico do curso de licenciatura em química e foram feitas discussões à luz das questões de direitos humanos no âmbito da formação docente dos alunos do curso de licenciatura em química do Ifpi Campus Teresina Central.

Quadro 01: disciplinas do curso de licenciatura em química que viabilizam as discussões de direitos humanos, políticas de inclusão e diversidade em consonância ao semestre que são ofertadas no Instituto Federal do Piauí.

\begin{tabular}{|c|c|}
\hline Disciplina & Semestre \\
\hline Filosofia da Educação & $1^{\circ}$ \\
\hline Sociologia da Educação & $2^{\circ}$ \\
\hline Política e organização da educação básica & $3^{\circ}$ \\
\hline Educação Especial & $5^{\circ}$ \\
\hline Libras & $6^{\circ}$ \\
\hline Educação e direitos humanos, inclusão e diversidade & $7^{\circ}$ \\
\hline
\end{tabular}

Fonte: Projeto Pedagógico do curso de licenciatura em química do IFPI Campus Teresina Central (2016)

De acordo com a tabela 01, pode-se identificar as disciplinas que viabilizam as discussões acerca dos direitos humanos na formação de professores de Química do Instituto, observou-se que estas disciplinas cumprem o papel de fomentar o caráter da educação em direitos humanos neste processo de formação docente.

Uma vez que estas disciplinas apresentam conteúdos, competências e habilidades que favorecem a promoção de discussões sobre direitos humanos, esses fatores não são suficientes para afirmar que estas discussões são realizadas, vale ressaltar a necessidade de não só direcionar os currículos escolares com a finalidade de favorecer uma cultura de direitos, mas também que promova uma formação voltada para uma educação problematizadora, dialógica, humanizadora (DIAS; PORTO, 2010). 


\section{DIREITOS HUMANOS NA FORMAC̨ÃO DOS ALUNOS DO IFPI}

Quadro 02: Disciplinas Ofertadas x Competências e Habilidades

\begin{tabular}{|c|c|}
\hline Disciplina Ofertadas & Competências e Habilidades \\
\hline Filosofia da Educação & $\begin{array}{l}\text { Compreender a filosofia da educação como reflexão } \\
\text { crítica do fenômeno educacional; } \\
\text { Articular os pressupostos filosóficos com a teoria da } \\
\text { educação e a prática pedagógica na perspectiva de } \\
\text { uma atuação ética, democrática e plural; } \\
\text { Posicionar-se criticamente frente às diferentes forças, } \\
\text { interesses e contradições presentes na ação educativa; } \\
\text { Identificar no fenômeno educativo aspectos para } \\
\text { constituir uma postura investigativa, integrativa e } \\
\text { propositiva na realidade escolar. }\end{array}$ \\
\hline Sociologia da Educação & $\begin{array}{c}\text { Estabelecer a relação entre educação, sociedade e } \\
\text { cultura; } \\
\text { Analisar conceitos, valores e finalidades que } \\
\text { norteiam a educação na/e para a sociedade, } \\
\text { Identificar diferentes forças e interesses presentes na } \\
\text { sociedade diagnosticando contradições existentes } \\
\text { adotando postura propositiva de mudanças; } \\
\text { Refletir sobre a evolução das formas culturais do } \\
\text { homem e suas relações com a formação de } \\
\text { identidades socioculturais e com as diversidades } \\
\text { étnicas e raciais. } \\
\text { Discutir a relação dialética homem/mundo e a } \\
\text { importância dos conhecimentos, costumes, atitudes, } \\
\text { para a construção, sistematização e evolução de } \\
\text { conhecimentos e valores do ser humano, } \\
\text { considerando as problemáticas da sociedade } \\
\text { contemporânea }\end{array}$ \\
\hline Política e organização da educação básica & $\begin{array}{c}\text { Compreender o Plano Nacional de Educação; O } \\
\text { Estatuto da Criança e do Adolescente, lei n } 8.069 / 90 \\
\text { e suas garantias na escolarização; } \\
\text { Compreender as concepções e paradigmas } \\
\text { curriculares para a Educação Nacional; }\end{array}$ \\
\hline
\end{tabular}




\begin{tabular}{|c|c|}
\hline & $\begin{array}{l}\text { Refletir sobre as Diretrizes e políticas pertinentes à } \\
\text { educação ambiental, as relações étnicos raciais e } \\
\text { outras garantias legais. }\end{array}$ \\
\hline Educação Especial & 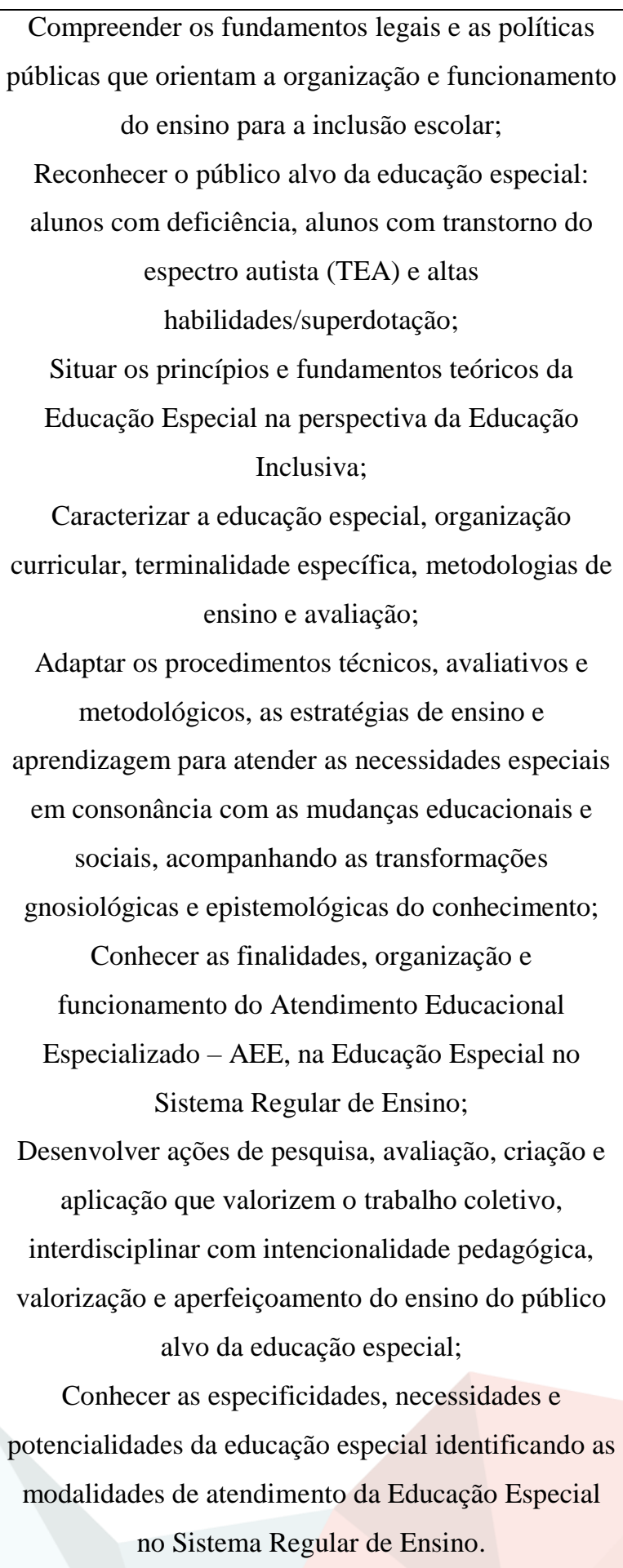 \\
\hline Libras & $\begin{array}{c}\text { Refletir sobre a trajetória histórica da educação } \\
\text { especial à educação inclusiva, destacando os modelos } \\
\text { de atendimento e seus paradigmas; }\end{array}$ \\
\hline
\end{tabular}




\section{DIREITOS HUMANOS NA FORMAC̨ÃO DOS ALUNOS DO IFPI}

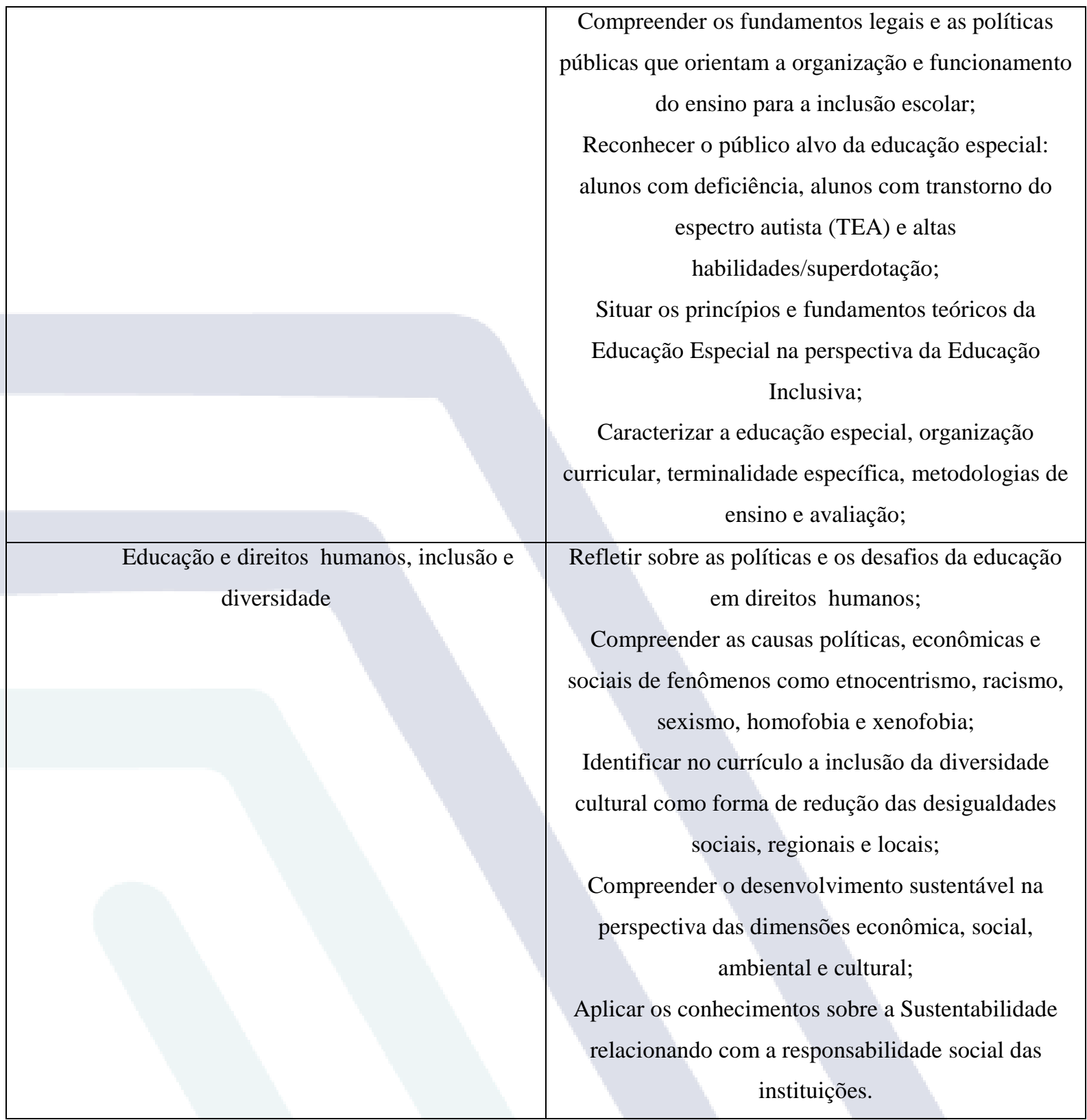

Fonte: Projeto Político Pedagógico do curso de Licenciatura em química (2016).

De acordo com o quadro 02, é possível identificar que as competências e as habilidades das disciplinas mencionadas dispostas no projeto pedagógico do curso cumprem o papel de favorecer as discussões de direitos humanos, diversidade e inclusão no processo de formação docente dos alunos de licenciatura em química, que de acordo com Sacavino (2009) a formação docente reflexiva à tal pedagogia, espera-se que o professor possa ser capaz de reconhecer as assimetrias de poder que ocorrem na sociedade, estabelecendo um julgamento sobre as lógicas de normalização das violações de direitos humanos e proponha estratégias de ensino que permitam dar voz aos grupos e sujeitos subalternizados.

De acordo com esta perspectiva Sacavino (2009) afirma que o docente é reconhecido como um agente sociocultural e político que é chamado a desenvolver uma pedagogia de 
empoderamento, entendida como uma pedagogia crítica e democrática orientada à mudança pessoal e social, portanto as competências e as habilidades dessas disciplinas colaboram para a construção desse agente sociocultural e político no âmbito da formação voltada para os direitos humanos, inclusão e diversidade.

De acordo com Candau e Sacavino (2013) verifica-se que ainda é tímida a introdução da temática dos direitos humanos no processo de formação de professores e educadores de forma generalizada, tanto referente a sua formação inicial, quanto na continuada. Apresentamse timidamente as instituições que trabalham sistematicamente nesta perspectiva.

Sabendo que trata-se de uma questão relevante a implantação de uma cultura dos direitos humanos, que possa permear as diversas práticas sociais. É necessário que as instituições de formação de educadores incorporem espaços, disciplinas, seminários, estágios entre outros espaços para que estas discussões ocorram. Portanto, é notório por meio da análise do PPP do Instituto que sua construção está pautada sumariamente na implantação dessas discussões.

Portanto, estas temáticas presentes nas disciplinas apontadas nos quadros 01 e 02 permitem o desenvolvimento das habilidades básicas relativas à cidadania, como a participação e a capacidade de tomada de decisão, pois trazem para a sala de aula discussões de aspectos sociais relevantes, que exigem dos alunos posicionamento crítico quanto a sua solução, colaborando para a formação de docentes como agentes sociocultural e político (CANDAU et al., 2016).

Portanto, de acordo com Sales (2009) os docentes devem participar mais efetivamente nas tomadas de decisões, tornando-se agentes de transformação críticoreflexivos, que atuam na sociedade, bem como nas instituições de ensino, cooperando positivamente para sua formação e transformação do meio que está inserido.

Consoante à Sales (2009) Fialho, Sousa e Lopes (2019) afirmam que através da EDH, os sujeitos são encorajados a perceber a si e ao próximo como cidadãos de direitos, sendo a escola um espaço de efetivação e de construção da democracia, dessa forma, ainda que a formação inicial desses docentes seja bastante relevante, é pertinente saber que ela é apenas um primeiro e um passo ínfimo, já que a real educação em direitos humanos apresenta-se de forma ininterrupta e, ao julgar que a sua função é estabelecer uma cultura de direitos humanos, deve ser continuamente repensada.

$\mathrm{Na}$ perspectiva de currículo como uma construção permanente o Projeto político pedagógico do Curso de Licenciatura em química desde sua implantação vem sendo adequado conforme as políticas e demandas na formação de professores aptos a aturem na educação 


\section{DIREITOS HUMANOS NA FORMACূÃO DOS ALUNOS DO IFPI}

básica. O projeto pedagógico do curso em vigência foi aprovado pelo Conselho Superior através da Portaria ${ }^{\circ} 286$ de 21 de dezembro de 2012 tem como finalidade atender as demandas das Diretrizes Curriculares Nacionais para a formação de professores licenciados em Química, aos princípios teórico-metodológicos que determina o PDI e demais regulamentações organizações didático-pedagógica do IFPI e aos objetivos e diretrizes institucionais fundamentados em dispositivos legais vigentes, por meio da interação das atividades de ensino, pesquisa e extensão.

\section{CONCLUSÃO}

Partindo da problemática: : qual a fundamentação que um licenciando recebe para lidar com questões como direitos humanos, políticas de inclusão e diversidade? O objetivo da pesquisa foi compreender a proposta de formação docente para atuação na perspectiva da educação para a diversidade e inclusão do curso de licenciatura em química ofertada pelo Instituto. Desta forma, foi abordada a situação-problema, trazendo uma análise do currículo do curso de licenciatura em química do IFPI, refletindo como ele prepara (ou deveria preparar) um professor com formação voltada para as questões de direitos humanos, inclusão e diversidade.

A partir das análises documentais da matriz curricular e do Projeto pedagógico do curso de licenciatura em química do IFPI foi possível constatar que estes documentos favorecem as discursões pertinentes às temáticas no âmbito da formação docente dos futuros professores de Química, portanto, estes documentos são considerados ferramentas efetivas norteadoras que estão mais próximas de favorecerem uma educação orientada por princípios da Educação em direitos humanos.

Nessa perspectiva, estes documentos asseguram uma formação para a Educação em direitos humanos, contribuindo para uma formação docente voltada para as questões de educação em direitos humanos, na medida em que se compreende é discutida novas formas de desenvolvimento, repensar as propostas para a EDH e de ação para controlar/subverter seus efeitos, articulando estratégias, políticas e práticas pedagógicas de respeito e solidariedade. 


\section{REFERÊNCIAS BIBLIOGRÁFICAS}

BOBBIO, N. A era dos direitos . Rio de Janeiro: Campus, 1992.

BRASIL. Constituição da República Federativa do Brasil. Brasília, DF: Congresso Nacional, 1988.

BRASIL, Secretaria de Direitos humanos da Presidência da República. Educação em Direitos humanos: Diretrizes Nacionais - Brasília. Secretaria Nacional de Promoção e Defesa dos Direitos humanos, 2013.

CANDAU, V.M;F; SACAVINO, S.B. Educação em Direitos humanos e formação de educadores. Educação, v. 36, n. 1, p. 59-66, 2013.

CANDAU, V. M.F, ANDRADE, M., da CONSOLAÇÃO LUCINDA, M., AMORIM, V., PAULO, I. A., e SACAVINO, S. B. Educação em Direitos humanos e formação de professores (as). Cortez Editora. 2016.

DE SALES, Jacira Teles. O projeto político pedagógico no Ensino Superior e o papel social de educadores no processo de aprendizagem. Revista Cereus, v. 1, n. 1, 2009.

DIAS, A. A., \& PORTO, R. D. C. C. A Pedagogia e a Educação em Direitos humanos: subsídios para a inserção da temática da Educação em Direitos humanos nos cursos de Pedagogia. João Pessoa: editora universitária da UFPB, 2010.

FIALHO, Lia Machado Fiuza; DE SOUSA, Francisca Genifer Andrade; LOPES, Tânia Maria Rodrigues. Juventudes e ensino médio: Direitos humanos e ensino para a diversidade. Revista Espaço Pedagógico, v. 26, n. 1, p. 238-259, 2019.

GADOTTI, Moacir. Pressupostos do projeto pedagógico. MEC, Anais da Conferência Nacional de Educação para Todos. Brasília. 1994.

GIL, A.C. Métodos e técnicas de pesquisa social. 6. ed. Editora Atlas SA, 2008.

MACIEL, T.S. Educação em Direitos humanos na formação de professores (as). Revista Interdisciplinar de Direitos humanos, v. 4, n. 2, p. 43-57, 2016.

Matriz Curricular do Curso de Licenciatura em química diurno Disponível em: http://www.ifpi.edu.br/cursos/QumicaDiurno.pdf acesso:10/06/2020.

OLIVEIRA, R. D. V. L.; QUEIROZ, G. R. P. C. Planejar com Direitos humanos na formação de professores de ciências. Areté - Revista Amazônica de Ensino de Ciências, Manaus, v.10, 


\section{DIREITOS HUMANOS NA FORMAC̨ÃO DOS ALUNOS DO IFPI}

n.22, p. 231-245, 2017.

SACAVINO, S. Educação em Direitos humanos e democracia. In: CANDAU, V. M.; (Orgs.). Educar em Direitos humanos: construir democracia. Rio de Janeiro: DP\&A, 2000.

SANTOS, W. SCHNETZLER, R. Educação em química - Compromisso com a cidadania,

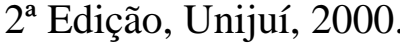

UNESCO. Declaración Mundial sobre Educación para Todos y el Marco de Acción para Satisfacer las Necesidades Básicas de Aprendizaje. 1990. Disponível em: http://www.unesco.org/ education/ntsunesco/pdf/JOMTIE_S.PDF. Acesso em: 12/05/2020.

UNESCO. Declaración de Salamanca de principios, política y práctica para las necesidades educativas especiales. 1994. Disponível em: http://www.unesco.org/education/pdf/SALAMA_S. PDF. Acesso em:12/05/2020.

VEIGA, I.P.A. Educacão básica: projeto político-pedagógico; Educação superior: projeto político pedagógico. Papirus Editora, 2004. 